\title{
Promoting the construction of "double creation" ecological environment with innovative spirit
}

\author{
Shanfu Yu \\ Huanghe S\&T University China (Henan) Innovation and Development Research Institute, \\ Zhengzhou Henan 450063 \\ Email:383322303@qq.com.
}

Keywords: maker culture, maker spirit, employee innovation vitality, cultural construction

\begin{abstract}
On September 26, 2018, the State Council issued the "Opinions of the State Council on Promoting the High-quality Development of Innovation and Entrepreneurship to Create an Upgraded Version of "Double Creation"'", The opinions point out that about China's innovation and entrepreneurship”There is still insufficient on innovation and entrepreneurship ecology" and other issues. Innovation is the first driving force to lead development.It is the grasp of the theme of innovation-driven and high-quality development that promoting the "double innovation" ecological environment upgrade with innovation spirit, and it is also a concrete measure to create an upgraded version of "double innovation". Based on a comprehensive analysis of the spirit of innovation, innovative elements, ecological environment, etc., combined with the situation of "double creation" ecological environment construction in Henan Province, this paper puts forward specific measures to optimize the "double innovation” ecological environment with innovative spirit.
\end{abstract}

\section{Introduction}

On July 12, 2017, Premier Keqiang Li for the first time mentioned the need to create a vibrant "double-created" ecological environment that is integrated, synergistic and shared, and to promote a comprehensive economic transformation through in-depth implementation of innovation-driven development strategies. On September 25 off the same year, the CPC Central Committee and the State Council jointly issued a document what brings entrepreneurship to a new height. The essence of entrepreneurship is innovation what is the unity of innovation spirit and innovative behavior and is also the source of independent innovation and the inexhaustible source of power. In September 2018, NDRC No. 32 document fully deployed the upgraded version of "Double Creation". The comprehensive optimization of the "double creation" ecological environment can enhance the consciousness of carrying forward the spirit of innovation and form a good "double creation" atmosphere to inspire people’ passion for innovation and entrepreneurship.

2. To carry forward the spirit of innovation is of great significance in promoting the construction of a “double-created" ecological environment

The spirit of innovation in the new era is accompanied by China's reform and development. It is 
not only the "lighthouse" but also the source of power that leads innovation and social change . Under the background of improving quality and efficiency, supply side reform, and innovation driven, carrying forward the spirit of innovation can fully stimulate the power, release the vitality, and promote the continuous improvement and optimization of the "double creation" ecological environment.

\subsection{The spirit of innovation provides spiritual protection for innovation-driven development}

Innovation is a high-level manifestation of human subjective initiative, a cognitive ability and practical ability, and provides an inexhaustible motive force for human progress and social development. Innovation is to break through the ideas and systems that constrain the development of productive forces through continuous innovation. The spirit of innovation leads innovation and development, and breaks the old and establishes new ones to promote the healthy development of society. Firstly, according to the general law of economic development, the core driving forces driving economic growth in different periods are different. China's economy has entered a new normal state at present, and the driving force of factor input has been weakening. It is difficult to drive economic development by means of extensive growth. We are now in the stage of attacking the growth mode from factor-driven to innovation-driven. Secondly, innovation has spawned a new industrial revolution. The fourth time industrial revolution is surging, innovation is everywhere, and new industrial changes have presented many new characteristics of the times, such as manufacturing service, the development of information network technology has changed the traditional service industry. All major companies are transforming from manufacturing to providing the ultimate solution and related services, although manufacturing still needs manufacturing, the service has become the main link of value-added. Finally, the spirit of innovation provides spiritual protection for innovation-driven development. Innovation-driven development relies on innovation, it leads the integration and optimization of production factors through the spirit of innovation, and drives the economic society to move forward steadily and rapidly. Innovation can not only solve the problem of factor efficiency decline caused by the increase of factor input, but also break through the bottleneck of factor allocation in economic development through the recombination of production factors.

\subsection{The spirit of innovation provides continuous motivation for the "double innovation" ecological environment upgrade}

Innovation is the primary productive force of social development, and the spirit of innovation provides an ideological foundation and a source of motivation for the overall optimization of the "double innovation" environment. Accurately understanding and grasping the significance of the spirit of innovation for the promotion of "double innovation" and the optimization of the ecological environment will contribute to the smooth progress of the current reform and help all people share the fruits of reform and development. First of all, carrying forward the spirit of innovation can enhance the self-confidence of the "double innovation" strategy. It need taking the spirit of innovation as the value guide of the "double innovation" strategy, adhering to the "double creation" value goal with innovative spirit, continuing to promote institutional innovation in the firm institutional confidence, and constantly providing institutional guarantee for the "double creation" cause, and we hope China's economy should developing steadily leaded by the spirit of the innovation. Secondly, carrying forward the spirit of innovation is conducive to adhering to the direction of the "double innovation" cause. We cultivate and promote the spirit of innovation, which is to strengthen the institutional self-confidence and theoretical self-confidence of "mass entrepreneurship and innovation". The spirit of innovation in the new era is the essence of the era of 
human social consciousness and values. It is derived from the great practice of China's "double creation" cause and has a positive reaction to the "double innovation" cause. Thirdly, promoting the spirit of innovation is conducive to optimizing the development environment of "double innovation". "Double-creation" not only hatched a group of emerging industries with hope in the future, but also provided a large number of employment opportunities; not only cultivated a group of outstanding talents for the whole society but also promoted the innovation and development of various industries. Fourthly, promoting the spirit of innovation is conducive to deepening reform and innovation. "Double Creation" is a systematic project. In the process of innovation, the innovation chain, industrial chain, ecological chain, capital chain and policy chain are mutually supportive. Reform and innovation must be fully deployed and promoted in an all-round way, so that enterprises should become the main body of transformation in the area of technological innovations and achievements. We should form a "double-created" ecological environment conducive to deepening reform and innovation through the formulation and implementation of incentives to support innovation policies. Finally, promoting the spirit of innovation is conducive to the cultivation of innovative talents. It is the key to Change the world economic map and guiding the economic development pattern of innovative talents. It profoundly reveals the dialectical relationship between talent development and innovation development, and points out the breakthrough and focus of economic development. Talent is the foundation and guarantee of innovation, and talents can lead innovation to drive development.

\section{Analysis of the ecological environment of "double creation" in Henan Province}

Since the launch of the "Double Creation" work, the number of entrepreneurs and entrepreneurs in Henan Province has reached a new height, ranking the first in the six provinces in the central region; the innovation and entrepreneurship index is constantly refreshing, and Henan Province ranks 11th in the country; as of the end of 2017, The number of three-board enterprises reached 378 in Henan Province, the number ranking second in the six provinces of the central region; Zhengzhou has repeatedly entered the list of innovation and entrepreneurship of national authorities, and Tencent's big data shows that the Zhengzhou City Young Index ranks sixth in the country. All kinds of "double-creative" subjects at all levels are guided by deepening reform and innovation and creating a strong "double-creative" environment.

\subsection{Characteristics of the "double creation" ecological environment in Henan Province}

First of all, the ecological environment of the regional "double creation" basement is continuously optimized. By gathering the advantages and resources of innovation and entrepreneurship, the region will ensure that all "double innovation" support policies take root in the local area, and a system of innovation which is diversified, distinctive and specialized will be established gradually, such as the "Double Creation" base project of Zhengzhou Airport Port Area. Innovate in terms of screening, business model selection, and financing channels, accelerate the transformation of scientific and technological achievements into the region, and guide scientific and technological innovation enterprises to gather in the region. Secondly, the ecological service chain of "double creation" bases in colleges and universities has been gradually improved. University research institutes fully exploit the advantages of talents and innovative resources, they combine their own school-running orientation to focus on the "double-created" resource elements to help regional economic development. For example, Zhengzhou University relies on the University Science and Technology Park to focus on creating eight platforms that including the platform for technological innovation and the platform for transforming scientific and technological achievements. Finally, the ecological environment of the "double creation" base of the enterprise 
was gradually established. For example, Henan Huanghe Cyclone Co. Ltd. has actively introduced a group of high-level leading talents with international vision and international leading achievements through the implementation of the provincial "Hundred Talents Program" and "Central Plains Scholars”.

\subsection{The problems in the “double creation” ecological environment in Henan Province}

Despite the fruitful exploration of innovation and entrepreneurship in Henan Province, there are still some outstanding problems in the development. First of all, in the development process of individual "double-creation" bases, from the leadership level to the individual level, there is a bias and misunderstanding of the "double creation". This lack of understanding is extremely unfavorable for the development of "double innovation" activities. Secondly, the differentiation and precision of the "double innovation" incentive policy are not prominent, the high-level technical workers are lacking, the senior technicians are too old, and the young high-skilled talents are in serious shortage. The spirit of the great country artisans needs to be strongly encouraged. Thirdly, a large number of "double-invasive" subjects are in the incubation period or the initial stage, and their "doubleinvasive" effects have not yet been fully presented. Finally, the supply and demand information of innovative resources such as talents, technology and industrial needs is asymmetrical, and capital and technical factors cannot be well combined.

\section{Analysis of innovation spirit and innovation factors}

The spirit of innovation and the elements of innovation have different interpretations from different angles, but the spirit of entrepreneurship and craftsmanship can fully lead the spirit of innovation. By analyzing the spirit of entrepreneurship and the spirit of craftsmen, it helps us to deeply understand the spirit of innovation.

\subsection{Innovative spirit of entrepreneurship}

The essence of entrepreneurship is innovation. Entrepreneurship is the unity of innovation spirit and innovative behavior. It is the source of independent innovation and the inexhaustible source of power. Innovation is the connotation of entrepreneurship, in the context of dramatic changes in market demand and game rules, enterprise production and service need to be personalized and

customized. The future model is not B2C but C2B. If enterprises want to survive in the context of Industry 4.0, they must innovate. They must carry forward entrepreneurship and do a good job in cultivating corporate spiritual culture. The effective promotion of the "double creation" business in Henan needs to give full play to the entrepreneurial spirit. Through the investigation of the "double creation" demonstration base in Henan Province, it is found that Hao Hua Jun Hua Group Co.Ltd. and Henan Huanghe Cyclone Co. Ltd. are practicing innovation and driving transformation and upgrading. The achievements in development are remarkable, and the entrepreneurial spirit of struggle and innovation is always everywhere. They dare to innovate and pragmatically start a business.

\subsection{Innovative spirit of craftsmanship}

The spirit of craftsmanship is a spirit of pursuing the ultimate. The enterprise needs to provide the motivation of the craftsman spirit. The Chinese people generally lack the craftsman spirit. In the past what caused us are unable to do something was not lack of technology. but was that we lacked the soil for innovation. Many people don't want to innovate, they don't want to pursue the 
ultimate, because they can't make more money. For a long time, Chinese consumers are more concerned about the price/performance ratio of goods. Enterprises can achieve the function of 80 with $1 / 3$ price, and they can gain market advantage and occupy the market without the pursuit of quality. However, as Chinese consumers pay more attention to quality, consumers will become more and more sensitive to product performance, but they are less sensitive to price. Past experience has become an obstacle to the development of enterprises. To eliminate, we must improve product quality and win the market by quality. This requires vigorous promotion of craftsmanship. The spirit of craftsmanship is an important belief in promoting social development, and it is a tireless cultivation and persistence. The spirit of creation is the direct driving force for the development of human society and the pursuit of a better life. The spirit of the craftsman is inseparable from the spirit of innovation, otherwise it will lack vitality, the spirit of the craftsman is like a strong torso, and the spirit of innovation is like a vital soul. Only the combination of the two can make a person's true potential real play out. Therefore, the spirit of craftsmen cannot be separated from the spirit of innovation, the spirit of innovation will lacks the soil for survival without the persistence of craftsmanship.

\section{Suggestions for escalating "double creation" ecological environment with innovative spirit \\ 5.1 Cultivating and promoting entrepreneurship}

Cultivating and promoting entrepreneurship is to help entrepreneurs establish noble moral sentiments and beliefs, to cultivate entrepreneurs' to love the nation and people by heart and mind. Entrepreneurship in the period should be build by pioneering, hardworking, and dedication, the confidence and determination of entrepreneurs to participate in reform and innovation should be improved, and the quality of enterprise development should be improved through continuous innovation.

First of all, innovation is the essence of entrepreneurship. The main goal of China's current economic development is still the transformation from old to new development power, mode transformation and structural adjustment, and supply-side reform and innovation-driven development to achieve high-quality development, which must rely on innovation to provides continuous momentum for the economy. Entrepreneurs are an important group that promotes innovation and stimulates market vitality. It creates a cultural atmosphere in which entrepreneurs are brave in innovation and initiative innovation, so that entrepreneurs can always maintain the enthusiasm and initiative of entrepreneurial innovation, leading enterprises to drive innovation and high quality development path.

Seconly, to stimulate the entrepreneurial spirit of enterprising. Enterprising is the source of entrepreneurship. Enterprising spirit is also the spirit of hard work, the driving force for promoting national progress in social development, and the basis for supporting enterprises to continuously innovate and develop and forge ahead. Since the launch of the "Double Creation" work, the entrepreneurial spirit of innovation, progress, dedication, responsibility and dedication has been continuously promoted, The promoting providing a driving force for innovation, and upgrading of enterprises. For example, Haohua Junhua Group Co., Ltd. takes "continuous improvement, longterm dedication to excellence " as the core concept, so that "artisan spirit, innovation spirit, contract spirit" can be reflected in the quality, brand value and service of products, the spirit dead them to make the most Good products,the best brands of the word, which also let customers and consumers feel, recognize, accept Junhua's product quality, brand value and service .HaoHua also create the long-lasting "DNA" and development momentum and let "double creation" work Achieve a normalized, project-oriented, and institutionalized ecosystem.

Thirdly, to promote the entrepreneurial spirit, General Secretary Xi Jinping has repeatedly 
stressed that party members and cadres should have the spirit of responsibility. Entrepreneurs should be the promoters of reform and innovation in the new era. They must bear in mind the mission and transcend themselves, they should put personal ideals and beliefs into the great practice of national rejuvenation, it contributes to the sustained and healthy development of the economy and society by taking the spirit and the feelings of the homeland. In the new era, the task of China's stable economic growth and structural adjustment is still very arduous, and it is necessary for the majority of entrepreneurs to come forward and be brave.

Finally, to tolerant the failure of entrepreneurs, and to creates an ecological environment that is tolerant of failure. The road to innovation and development is full of all kinds of variables. Entrepreneurs are always on the road. Success is certainly gratifying, but failure is sometimes inevitable. Our society does not lack followers. Everyone advocates "big heroes." However, we lack the proper respect and the respect for the people and things which behind the "big heroes", and sometime we will also "cold and sarcasm" for the people and things; in many cases, due to policy constraints, some government "double-creative" managers are working in "double creation" worried that the failure of the project will be pursued and not taken seriously, which will affect the timely and effective development of many projects, which are not conducive to the promotion of entrepreneurship. We must not only regard entrepreneurs as scientists, give the highest respect, but also establish a "double-creative" ecological environment that is tolerant of failure, we should establish a policy system of due diligence, and fully mobilize the enthusiasm and initiative of entrepreneurs and "double-creative" managers. So as to promote the "double innovation" work in depth.

\subsection{To cultivate and promote the spirit of craftsmen}

On May 8, 2015, the State Council issued the "Made in China 2025", which is the Chinese version of "Industry 4.0". To achieve the goal of the world's manufacturing powers, we must carry forward the spirit of artisans and grasp all the opportunities brought about by the new technological revolution. By overturning or changing lanes to improve our manufacturing capacity and manufacturing level, our ultimate aim is achieving high quality and green development

First, an ecological environment that respects the spirit of artisan should be created. Most of the feudal dynasties in China have advocated "learning and excellence", and the official position is serious. In the society dominated by the thought of heavy peasant and light business, artisans have been in the lower class of society and are classified as "three religions and nine streams". In 2017, China's GDP reached 827.12 billion Yuan, the economic growth rate is 6.9. Our target in 2018 is to increase by about 6.5. This provides conditions and foundation for our reform, innovation, and transformation. The whole society has formed a good social atmosphere that respects craftsmen and advocates the spirit of artisans. Secondly, innovate the institutional mechanism of the craftsmanship spirit. Colleges and universities should constantly reform and innovate, accelerate the development of high-skilled personnel training platform that is compatible with technological progress and social needs. Colleges and universities also should fully mobilize and integrate various resources, the advantages of talents and technology agglomeration should be fully utilized to explore the "skilldriven, skill-level, and orientation-oriented" high-skilled personnel training model, and implement targeted skills cultivation projects. We should in-depth integration of production teaching with "artisan spirit", with the needs of society to train engineers, senior technicians and high-quality applied talents with the spirit of artisans. Finally, to improve the incentive mechanism for promoting the spirit of artisans. To promote the spirit of artisans, it is necessary to establish a scientific and effective incentive and guarantee system to provide guarantees for the achievements and efforts of the craftsmen. Through the improvement of legislation and law enforcement to 
strengthen the protection of artisans and related intellectual property rights and technical patents, the system protects the legitimate rights and interests of traditional craftsmen from infringement; it can through modern technical means that establishes and improves the trace ability system of craftsmen's works, and enhances the sense of responsibility of craftsmen and A sense of accomplishment; the establishment of a craftsman reward , the introduction of incentive policies, the establishment of industry pacesetters, Above Multi-strategys encourage artisans to innovate.

\section{Conclusions}

The spirit of innovation is essential to the overall optimization of the "double innovation" environment. By fostering and promoting entrepreneurship and craftsmanship, we can form a good "double-creative" ecosystem in the whole society and provide a good ecological environment for comprehensive and deep reform.

\section{Acknowledgements}

Fund Project: 2018 Henan Provincial Government Decision-making Research Tendering Project "Building a Double-Creation Base Upgrade Version" to Promote the High-Quality Development of Henan Economy” (2018B049); Henan Province's Ninth Key Discipline "Regional Economics” (Yu Jiaogao ( 2018) No. 119); 2017 Teaching Reform Project of Huanghe Science and Technology College: Project No.: JGYB2017015, Project name: Research on Innovation of Logistics Management Personnel Training of Model Application-oriented University in the Background of Innovation and Entrepreneurship.

\section{References}

[1] Keqiang Li, 2017.Further fostering the "double creation" ecological environment of integration and synergy sharing,China Economics, 2017 (10): 4.

[2] Research Group of Entrepreneurship Research of Guizhou University, 2018.Entrepreneurial Innovation Spirit behind the Development of Blockchain Technology. Guizhou Daily, 2018-02-13 (011).

[3] Meilan Ye, Guixiang Chen, 2016.The Contemporary Value Implication of Craftsman Spirit and the Choice of Its Realization Path. Higher Education Exploration, 2016(10): 27-31.

[4] [Day] Qiushan Lihui, Craftsman spirit. Xiaoli Chen, 2015 translated. Beijing: CITIC Publishing Group, 2015: 11, 3.

[5]Xiaoxian Jiang, Kaibiao Xiang, Wang Peng, 2018.Regional Economic Development and Entrepreneurship Configuration. Enterprise Economy, 2018 (01): 31-37. 